\title{
Social dysfunction and skills in schizophrenia: relationship with treatment response and severity of psychopathology
}

\author{
Silvia Scemes¹, Mariangela Gentil Savoia ${ }^{1}$, Zilda Del Prette², Paulo Mestriner¹, Aline Roberta da Silva¹, Hélio Elkis¹ \\ 1 Institute of Psychiatry, Hospital das Clínicas, University of São Paulo Medical School (IPq-HCFMUSP), São Paulo, SP, Brazil. \\ 2 Federal University of São Carlos (UFSCar), Center for Biological and Health Sciences, Department of Psychology, São Carlos, SP, Brazil.
}

Received: 8/25/2016 - Accepted: 10/31/2016

DOI: 10.1590/0101-60830000000095

\begin{abstract}
Background: Social dysfunction is an important outcome for schizophrenia and can be measured by the evaluation of social skills. Objectives: To compare social skills in patients with schizophrenia classified according the degree of treatment response and severity of psychopathology with normative controls by using the Del Prette Social Skills Inventory (SSI). Methods: Cross-sectional study where the 38 questions SSI was applied to 62 outpatients with schizophrenia and compared with data of 99 normal controls from the general population. The SSI was evaluated by five domains. Psychopathology was measured by the Positive and Negative Syndrome Scale (PANSS). Patients were classified as Treatment Resistant (TRS) and Non Treatment Resistant (NTRS) by the International Psychopharmacology Algorithm Project (IPAP) criteria. ANCOVA was used to control for demographic differences between populations. Results: Patients showed significantly more impaired than controls except for aggressiveness control. When variables such as age, age of onset, schooling or medication dose entered as covariates, differences between controls and patients, or TRS with NTRS, almost disappeared. The SSI and PANSS showed an inverse relationship between their domains. Discussion: The SSI may represent a useful tool for evaluation of social skills in schizophrenia. Antipsychotics may exert a protective effect on social skills.
\end{abstract}

Scemes S et al. / Arch Clin Psychiatry. 2016;43(5):107-11

Keywords: Schizophrenia, social dysfunction, social skills, scales, social skills inventory.

\section{Introduction}

Schizophrenia is a severe mental disorder which affects $1 \%$ of the population and it is associated with personal, social and family burden. The diagnostic of schizophrenia involves a constellation of signs and symptoms associated with impaired occupational or social functioning. Patients with schizophrenia show impairments is several areas or domains of psychopathology such as psychotic (delusions and hallucinations), disorganization (thought disorders), negative symptoms (blunted affect, lack of motivation and social withdrawal), affective symptoms (depression or mania) and cognitive impairment (abstraction, attention, memory and executive functions) $)^{1,2}$.

The treatment of schizophrenia involves a combination of medication and psychosocial interventions such as family orientation, cognitive behavior therapy and social skills training. Patients with schizophrenia are treated with antipsychotics, either or first or second generation, and are considered responders or nontreatment resistant (NTRS) when they improve certain symptoms (e.g. psychotic symptoms) after one or two adequate treatments. When patients do not respond to two adequate treatments they are considered refractory or treatment resistant (TRS) and are eligible to receive clozapine, which is the drug of choice for such condition. Generally patients with TRS are considered more severely compromised than those with NTRS3.

It well known that impairment of social functions is a common feature of schizophrenia and is present from the early stages of the illness. In the past poor social functioning have been described in as core feature of Dementia Praecox by Kraepelin and as well as psychotic or negative symptoms, they also considered hallmarks of the disorder and are required for modern diagnosis schizophrenia, as for example in the DSM 5 criteria ${ }^{2,4}$.

Social skills are defined as micro components of social functions and include everyday conversations, encounters, and relationships that people have with each other. Social skills include the ability to give and obtain information and to express and exchange attitudes, opinions, and feelings ${ }^{4,5}$.
Social skills are generally compromised in patients with schizophrenia and the degrees of impairment correlate with some domains of psychopathology such as negative or cognitive symptoms. The treatment of social impairment using social skills training showed to improve social function as well as negative symptoms in patient with schizophrenia ${ }^{6,7}$.

The measurement of social skills represents an important outcome variable for the evaluation of social dysfunction in patients with schizophrenia. Their evaluation comprise methods such as observation, role-playing, interviews, rating scales and selfassessment, which are employed depending on the type of outcome as well as the cultural norms of the studied population ${ }^{5}$.

Del Prette et al. developed the Social Skills Inventory (SSI - DelPrette or SSI) in order to assess social abilities in a normal population in Brazil. The SSI is a self-report instrument which assesses the repertoire of social skills of daily interpersonal situations. It was initially validated for college population (18-25 years) but it is also used to assess social performance in adults 8,9 .

The SSI has been employed extensively to evaluate social skills in non-psychiatric populations ${ }^{8,9}$, but its use in psychiatric patients is not well appreciated since only one study used the instrument to evaluate patients with bipolar disorders in comparison with normal controls ${ }^{10}$ and, to our knowledge, it has never been used to evaluate the degree of impairment of social function in patients with schizophrenia.

Therefore the primary aim of the present is study is test whether social skills are compromised in patients with schizophrenia in comparison with normal controls by using the SSI. The secondary aim is the investigation of the relationship between the SSI with dimensions of psychopathology, as measured by the PANSS, which is the standard scale for measurement of severity of symptoms in schizophrenia ${ }^{11}$, as well treatment response to antipsychotics either in patients with TRS or NTRS. We hypothesize that SSI and the PANSS have an inverse relationship and that patients with TRS will be more compromised than patients with NTRS regarding their social abilities. 


\section{Methods}

\section{Study design}

This is cross-sectional study performed at the Schizophrenia Research Program of the Institute of Psychiatry of University of São Paulo (Projesq-IPq-HC) and is part of larger study originally aimed to investigate the efficacy of social skills training on negative symptoms in patients with TRS funded by Fundação de Amparo à Pesquisa do Estado de São Paulo (São Paulo Research Support Foundation) (Fapesp) (2009/13934-6).

\section{Study population and assessment}

Patients were recruited from the outpatient clinic of the ProjesqIPq-HC and signed an informed consent agreement to participate and have been diagnosed with schizophrenia based on the DSM IV TR criteria ${ }^{12}$. Patients were excluded if they had documented history of alcohol or drug dependence, brain trauma, mental retardation or severe cognitive impairment. Patients were defined as having TRS according to the International Psychopharmacology Algorithm Project (IPAP) i.e. failure to respond to at least two adequate trials with antipsychotics with the 4-6 weeks duration ${ }^{13}$ and were receiving clozapine, which is the standard medication for such condition ${ }^{14}$. Additionally data was obtained from the psychiatry in charge of the patient, as well as chart review. NTRS patients were defined as those who have responded to one or two treatment with antipsychotics according to the IPAP, and were in stable conditions, receiving non-clozapine antipsychotics. In order to compare antipsychotic treatment regimens, doses were transformed into chlorpromazine equivalents using parameters proposed by Woods ${ }^{15,16}$.

Sixty two patients with schizophrenia were included: thirty three met criteria for TRS while twenty nine were NTRS. Data of ninety nine normal controls derived from the general population (population or normative controls) and who were evaluated for the purpose of re-validation by the SSI - Del-Prette was provided by one of the authors of SSI - Del-Prette inventory who is also a co-author of the present study (ZDP).

\section{Instruments}

The SSI is a self-report questionnaire composed of 38 items, each of them describing an interactive social situation and a possible reaction to it. The instrument was developed to evaluate social skills for adult general population and was validated for the Brazilian population ${ }^{8,9}$. Subjects are asked to estimate how often they react to that particular situation, considering the number of times he or she faced that situation. Responses are rated according to a Likert scale ranging from zero (never or rarely) to four (always or very frequently). Some items have a negative meaning, i.e., the higher the score, the lower the skill. In those cases, the score must be inverted. Results can be measured either the total score as well as percentiles 8,9 . Higher values of the SSI mean higher social skills abilities. The SSI is usually self-administrated or by a rater, but in the present study it was administrated by trained psychologists blinded for the treatment condition of the patients. The raters read the questions for the patients and took notes about the content of their responses. Questions were repeated as much as necessary since it is well known that patients with schizophrenia can have various degrees of cognitive impairment. The SSI comprises five factors or domains of SSI obtained through factor analysis. These factors and their meaning are displayed in Table 1.

Psychopathology was evaluated by the Positive and Negative Syndrome Scale (PANSS) which comprises 3 subscales (Positive, Negative, General Psychopathology), which evaluate psychotic, negative and general psychopathological symptoms, respectively ${ }^{11}$.
Table 1. Factors or domains of the SSI - Del-Prette8-10

\begin{tabular}{|c|c|c|}
\hline Domain & Name & Description \\
\hline F1 & $\begin{array}{l}\text { Coping and self- } \\
\text { assertion with risk }\end{array}$ & $\begin{array}{l}\text { Evaluates assertiveness in interpersonal } \\
\text { situations, to safeguard the rights of the } \\
\text { individual and maintain self-esteem (e.g. } \\
\text { 'When a friend to whom l've lent some } \\
\text { money forgets to give it back, I find a way to } \\
\text { remind him/her') }\end{array}$ \\
\hline F2 & $\begin{array}{l}\text { Self-assertion in the } \\
\text { expression of positive } \\
\text { affect }\end{array}$ & $\begin{array}{l}\text { Analyses self-confidence in the expression } \\
\text { of positive feeling, the items depict the } \\
\text { need for positive interpersonal feedback } \\
\text { and affirmation of self-worth (e.g. 'When } \\
\text { someone does something I think is good, } \\
\text { even if it is not directly related to me, I } \\
\text { mention it, praising him/her at the first } \\
\text { opportunity') }\end{array}$ \\
\hline F3 & $\begin{array}{l}\text { Conversation and } \\
\text { social confidence }\end{array}$ & $\begin{array}{l}\text { Evaluates conversational skill and social } \\
\text { boldness, and its items portray neutral } \\
\text { situations of initial social encounters (e.g. } \\
\text { 'When I am with a person who I have } \\
\text { just met, it is difficult for me to keep an } \\
\text { interesting conversation going') }\end{array}$ \\
\hline F4 & $\begin{array}{l}\text { Self-exposure to } \\
\text { unknown people and } \\
\text { new situations }\end{array}$ & $\begin{array}{l}\text { Evaluate social openness to new people } \\
\text { and new situations, describe situations that } \\
\text { involve interacting with new people (e.g. } \\
\text { 'I avoid asking questions of people I don't } \\
\text { know') }\end{array}$ \\
\hline F5 & $\begin{array}{l}\text { Self-control of } \\
\text { aggressiveness }\end{array}$ & $\begin{array}{l}\text { Evaluate self-control of aggressiveness } \\
\text { and individual reactions to aversive stimuli } \\
\text { that require the management of anger and } \\
\text { aggressiveness (e.g. 'When my schoolmates } \\
\text { or work colleagues tease me, I don't let it } \\
\text { bother me') }\end{array}$ \\
\hline
\end{tabular}

\section{Statistical evaluation}

Groups were compared using t tests, chi square or ANOVA when appropriate. Variables which differed significantly between groups entered as covariates for the comparisons between domains of the SSI using an ANCOVA model followed by Bonferroni pairwise comparison tests. Comparison between patients with TRS and non TRS were performed using medication doses and age of onset as covariates. The relationship between SSI and the PANSS was evaluated by Pearson correlation coefficients. The level of significance was defined as 0.05 . The SPSS 22.0 software was used to run all the analyses.

\section{Ethical aspects}

The study was approved by the Internal Review Board of the University of São Paulo General Hospital (Protocol number 0761/08) and registered at site of the Clinicaltrials.gov (NCT 0079 1882).

\section{Results}

As can be observed in Table 2 normal controls were 49 males and 50 females, had a mean (sd) age of $31.62(10.44)$ years and 14.49 (2.48) years of schooling, while patients with schizophrenia were 24 males and 38 females, had a mean age of 40.29 (10.46) years and had 10.31 (2.37) years of schooling. As expected the whole sample of patients with schizophrenia $(n=62)$ showed significant less social abilities than controls in all domains of the SSI except for factor F5 (self-control of aggressiveness). However patients and controls differed significantly in terms of age and schooling (Table 2). 
Table 2. Comparison between normative controls and the whole sample of patients with schizophrenia in terms of demographic variables and Factors of the SSI

\begin{tabular}{|c|c|c|c|c|}
\hline $\begin{array}{l}\text { Factors* of the SSI and } \\
\text { demographic variables }\end{array}$ & $\begin{array}{l}\text { Controls } \\
(\mathrm{n}=99)\end{array}$ & $\begin{array}{l}\text { Patients with schizophrenia } \\
\qquad(n=62)\end{array}$ & Statistical test & $\begin{array}{l}\text { Significance } \\
\text { (p value) }\end{array}$ \\
\hline Age & $31.62(10.44)$ & $40.29(10.46)$ & $t=-5.13$ & 0.00 \\
\hline Gender & 49 males; 50 females & 24 males; 38 females & Chi-square = 2.14 & 0.14 \\
\hline Schooling (in years) & $14.49(2.48)$ & $10.31(2.37)$ & $t=10.61$ & 0.00 \\
\hline F1 & $9.88(2.93)$ & 7.46 (3.29) & $t=4.86$ & 0.00 \\
\hline F2 & $9.11(1.72)$ & $6.73(2.80)$ & $t=6.02$ & 0.00 \\
\hline F3 & $6.55(2.17)$ & $5.89(1.83)$ & $t=2.01$ & 0.05 \\
\hline F4 & $3.24(1.27)$ & $2.22(1.49)$ & $t=4.62$ & 0.00 \\
\hline F5 & $0.96(0.70)$ & $1.33(0.69)$ & $t=-3.31$ & 0.00 \\
\hline
\end{tabular}

* Factors names: see method section.

Subsequently we compared controls with patients with schizophrenia classified according to treatment response (TRS vs NTRS). Thus thirty three patients composed the TRS group (24 males and 9 females), they had a mean age of 36.42 (7.71) years, the age of onset of illness was 18.97 (4.99) years, they had been ill for 17.45 (7.45) years, had 10.52 (2.15) of schooling. The NTRS group patients was composed by 14 males and 15 females, had a mean age of 44.69 (11.97) years, an age of onset of illness of 31.70 (15.09), a duration of illness of 13.52 (10.75) years and had 10.07 (2.72) years of schooling. As can be observed in Table 3 patients differed marginally in terms of gender $(p=0.05)$ but significantly in terms of age $(\mathrm{p}=0.00)$ and schooling $(\mathrm{p}=0.00)$. TRS patients and NTRS patients differed significantly in terms of antipsychotic doses when converted into chlorpromazine equivalents $(\mathrm{p}=0.00)$.

However the comparisons of SSI domains of patients according to the response to treatment (TRS and NTRS) with controls, with by age, gender and schooling as covariates, showed that NTRS patients were significantly more impaired on three domains: F1 (coping and self-assertion with risk) (0.02), F2 (expression of positive affect)
(0.00) and F4 (self-exposure to unknown people and new situations) (0.01), but were preserved on the F3 domain (conversation and social confidence) and on the F5 domain (self-control of aggressiveness). The comparison between controls and TRS showed that patients with such condition were more impaired on two domains F2 (0.00) and F3 (0.00), but showed no differences with controls on domains F1, F4 and F5 (Table 4).

The comparison between TRS and NTRS groups with age of onset and antipsychotic doses as covariates showed no differences between these groups in terms of their social abilities, as measured by the SSI (Table 5).

As predicted the majority of the correlations between the five social skills domains of the SSI and the three PANSS subscales showed to be negative. However, in the majority of cases, they were small and non-significant. Only three correlations showed to be more robust as is the case of F1 (copying and self-assertion with risk) with the General Psychopathology subscale and F3 (conversation and social confidence) with the Positive and General Psychopathology, respectively (Table 6).

Table 3. Comparisons Normal Controls and patients with Treatment Resistant and Non Treatment Resistant in terms of demographic variables, antipsychotic medication severity of psychopathology by the PANSS

\begin{tabular}{|l|c|c|c|c|c|}
\hline & $\begin{array}{c}\text { Controls } \\
(\mathrm{N}=99)\end{array}$ & $\begin{array}{c}\text { TRS } \\
(\mathrm{N}=33)\end{array}$ & $\begin{array}{c}\text { Non TRS } \\
(\mathrm{N}=29)\end{array}$ & $\begin{array}{c}\text { Statistical } \\
\text { Test }\end{array}$ & $\begin{array}{c}\text { Significance } \\
(\mathrm{p})\end{array}$ \\
\hline Age (in years) & $31.62(10.44)$ & $36.42(7.71)$ & $44.69(11.97)$ & $\mathrm{F}=19.00$ & $0.00^{*}$ \\
\hline Gender & $\mathrm{M}=49 ; \mathrm{F}=50$ & $\mathrm{M}=24 ; \mathrm{F}=9$ & $\mathrm{M}=14 ; \mathrm{F}=15$ & Chi-square $=5.85$ & $0.05^{*}$ \\
\hline Schooling (in years) & $14.49(2.48)$ & $10.52(2.15)$ & $10.07(2.72)$ & $\mathrm{F}=56.42$ & $0.00^{*}$ \\
\hline Age of onset of illness (in years) & - & $18.97(4.99)$ & $31.70(15.09)$ & $\mathrm{t}=-4.20$ & $0.00^{*}$ \\
\hline Duration of illness (in years) & - & $17.45(7.45)$ & $13.52(10.75)$ & $\mathrm{t}=1.61$ & 0.15 \\
\hline $\begin{array}{l}\text { Antipsychotic medication } \\
\text { (chlorpromazine equivalents) } \mathrm{mg} / \text { day }\end{array}$ & - & $1132.81(309.9)$ & $347.69(194.7)$ & $\mathrm{t}=11.75$ & $0.00^{*}$ \\
\hline PANSS positive & - & $12.47(3.87)$ & $9.50(3.54)$ & $\mathrm{t}=1.06$ & \\
\hline PANSS negative & - & $27.50(5.62)$ & $16.50(4.95)$ & $\mathrm{t}=2.70$ & 0.30 \\
\hline PANSS general & - & $29.97(6.88)$ & $33.50(6.36)$ & $\mathrm{t}=-0.71$ & 0.11 \\
\hline PANSS total & - & $69.94(12.60)$ & $59.50(14.85)$ & $\mathrm{t}=1.13$ & 0.49 \\
\hline
\end{tabular}

* Significant pairwise comparisons. TRS: Treatment Resistant Schizophrenia; NTRS: Non Treatment Resistant Schizophrenia; PANSS: Positive and Negative Syndrome Scale.

Table 4. Comparisons of Factors of the SSI in Normal Controls versus patients with Treatment Resistant and Non Treatment Resistant, controlling for Age, Gender and Schooling

\begin{tabular}{|l|c|c|c|c|c|c|c|}
\hline Factor* & $\begin{array}{c}\text { Controls } \\
(\mathrm{N}=99)\end{array}$ & $\begin{array}{c}\text { TRS } \\
(\mathrm{N}=33)\end{array}$ & $\begin{array}{c}\text { NTRS } \\
(\mathrm{N}=29)\end{array}$ & $\begin{array}{c}\text { ANCOVA } \\
\text { Model }\end{array}$ & \multicolumn{2}{|c|}{ Bonferroni pairwise comparisons } \\
\cline { 2 - 8 } & Mean (SD) & Mean (SD) & Mean (SD) & F; $p$ & Controls vs. TRS** & Controls vs. NTRS** & TRS vs NTRS** \\
\hline F1 & $9.88(2.93)$ & $7.85(3.33)$ & $7.02(3.24)$ & $5.87 ; 0.00$ & 0.09 & 0.02 & 1.00 \\
\hline F2 & $9.11(1.72)$ & $6.30(3.10)$ & $7.22(2.38)$ & $11.33 ; 0.00$ & 0.00 & 0.00 & 1.00 \\
\hline F3 & $6.56(2.17)$ & $5.65(2.09)$ & $6.16(1.47)$ & $3.99 ; 0.00$ & 0.00 & 0.11 & 0.81 \\
\hline F4 & $3.24(1.27)$ & $2.50(1.41)$ & $1.91(1.54)$ & $5.23 ; 0.00$ & 0.09 & 0.01 & 0.59 \\
\hline F5 & $0.96(0.70)$ & $1.31(0.59)$ & $1.36(0.79)$ & $4.95 ; 0.00$ & 1.00 & 0.73 & 1.00 \\
\hline
\end{tabular}

* Factors names (see method section); ${ }^{*}$ Significant pairwise comparisons in bold.

TRS: Treatment Resistant Schizophrenia; NTRS: Non Treatment Resistant Schizophrenia. 
Table 5. Factors of SSI in Treatment Resistant in comparison with NonTreatment Resistant patients with Schizophrenia, controlling for age of onset and medication dose

\begin{tabular}{|l|c|c|c|c|}
\hline Factor* & TRS (N = 33) & NTRS (N = 29) & $\begin{array}{c}\text { ANCOVA } \\
\text { Model }\end{array}$ & $\begin{array}{c}\text { TRS vs NTRS } \\
\text { Bonferroni } \\
\text { Pairwise } \\
\text { Comparison } \\
\text { ( } \mathrm{p} \text { value) }\end{array}$ \\
\hline & Mean (SD) & Mean (SD) & F; $p$ & \\
\hline F1 & $7.90(3.37)$ & $7.09(3.23)$ & $0.84 ; 0.48$ & 0.20 \\
\hline F2 & $6.40(3.10)$ & $7.16(2.40)$ & $0.71 ; 0.55$ & 0.75 \\
\hline F3 & $5.70(2.11)$ & $6.21(1.43)$ & $0.75 ; 0.53$ & 0.75 \\
\hline F4 & $2.50(1.43)$ & $1.81(1.60)$ & $0.97 ; 0.42$ & 0.33 \\
\hline F5 & $1.32(0.60)$ & $1.36(0.78)$ & $0.22 ; 0.89$ & 0.83 \\
\hline
\end{tabular}

* Factors names: see method section.

TRS: Treatment Resistant Schizophrenia; NTRS: Non Treatment Resistant Schizophrenia.

Table 6. Correlation coefficients and respective significances between SSI domains and the subscales of Positive and Negative Syndrome Scale (PANSS)

\begin{tabular}{|l|c|c|c|}
\hline $\begin{array}{l}\text { SSI } \\
\text { Factors* }\end{array}$ & PANSS Positive & PANSS Negative & $\begin{array}{c}\text { PANSS General } \\
\text { Psychopathology }\end{array}$ \\
\hline F1 & $-0.034 ; p=0.85$ & $-0.22 ; p=0.22$ & $-0,37 ; p=0.03$ \\
\hline F2 & $-0.03 ; p=0.85$ & $-1.94 ; p=0.27$ & $-0.15 ; p=0.41$ \\
\hline F3 & $-0.40 ; p=0.02$ & $0.02 ; p=0.90$ & $-0.36 ; p=0.04$ \\
\hline F4 & $-0.03 ; p=0.90$ & $-0.13 ; p=0.47$ & $-0.07 ; p=0.72$ \\
\hline F5 & $-0.19 ; p=0.29$ & $-0.09 ; p=0.61$ & $-0.01 ; p=0.94$ \\
\hline
\end{tabular}

* Factors names: see method section. PANSS: Positive and Negative Syndrome Scale.

\section{Discussion}

The present study found that, as expected, patients with schizophrenia, when compared with normal controls, show more pronounced impairments in various domains of social skills abilities as measured by the SSI - Del-Prette inventory. However, patients performed better than controls on the selfcontrol of aggressiveness (F5) which may be explained by the fact that antipsychotics exert control over aggression, particularly clozapine ${ }^{17}$ which was received by half of the sample of the patients. Another explanation could be the fact that the controls were younger than patients and, probably, more prone to impulsiveness.

The comparison between patients with controls controlling by age, gender and schooling showed that patients, regardless the use of clozapine or non-clozapine antipsychotics, exhibit impairments in certain social skills areas, such as the expression of positive affects (F2 domain) but are preserved in other aspects such as coping with risk situations (F1 domain), conversational skills (F3 domain), exposure to unknown situations or people (F4 domain) as well as ability to control their aggressiveness (F5 domain).

An explanation for this fact could also rely on the role of antipsychotics, which is known to exert a positive influence on social skills, a phenomenon observed many years ago when phenothiazines, where introduced for the treatment of schizophrenia ${ }^{18}$. More recently randomized controlled trials of social skills training have shown that the greatest improvement in social outcomes occurred when the training was combined with antipsychotic medication ${ }^{19}$.

Therefore we found no difference than controls in skills which involve assertiveness, conversational skills, self-exposure to new situations and control of aggression, as evaluated by the SSI when age, gender and schooling were controlled which may reflect the positive influence of the use of antipsychotics which may improve these abilities.

However the only domain were controls showed better results than patients was the expression of positive affects (F2) and it well known that deficits in the expression of affect was considered one of the fundamental symptoms of schizophrenia by Bleuler and it is now defined as a persistent or primary negative symptom ${ }^{20}$ for which the efficacy of antipsychotics it not proven ${ }^{21,22}$.

Another problem is related to the distinction between primary from secondary negative symptoms (e.g. social withdrawal caused by auditory hallucinations) and this distinction is generally difficult to perform. Therefore a deficit in the expression of emotions may represent either a primary or a secondary negative symptom ${ }^{20}$.

It is also important to mention that primary negative symptoms also do not improve with social skills training as it was observed in patients with deficit syndrome, characterized by a predominance of primary negative symptoms, in comparison with patients with non-deficit syndrome ${ }^{23,24}$.

The SSI showed to correlate inversely with the PANSS meaning that, in patients with schizophrenia, the higher the severity of their symptoms, the lower will be their skills abilities. However the fact the correlations showed to be small and no-significant which may reflect that social skills are influenced by other factors, as for example, cultural and situational aspects 9 . It is noteworthy that the domain of conversation and social confidence (F3) was inversely and significantly correlated with positive and general psychopathological symptoms, which may illustrate the influence exerted by certain symptoms such as delusions and hallucinations (positive or psychotic symptoms) or anxiety or depression (general psychopathology) on this domain.

This study has several limitations, one of then the fact that it is a cross sectional study, where conclusions about causation are limited ${ }^{25}$. Another aspect is related to the use of the SSI in patients with schizophrenia, an instrument primarily conceived for the evaluation of social skills in non-psychiatric populations ${ }^{8,9}$.

The present study was not designed to validate the SSI in schizophrenia but it showed to be an useful instrument for the purpose of measuring social abilities in patients with such disorder. Additionally is important to emphasize that the evaluation of social skills in this population is very heterogeneous ${ }^{7}$ and there is no an instrument like the PANSS, which is considered the gold standard scale for the measurement of severity of symptoms in schizophrenia ${ }^{26}$

Another important aspect is that the SSI is self-administered but in the case of the present study it was administered with the help of the psychologists since it is well known that patients with schizophrenia suffers varying degrees of cognitive impairments ${ }^{27}$. The relationship between with social skills with cognitive impairment was not evaluated in the present study, but will be presented as part of the results in a forthcoming publication of our main study, a randomized controlled trial which evaluated the impact of social skills training on the severity of negative symptoms in patients with TRS.

Finally it is possible that the use of normative controls and not regular controls may have influenced results. However Almeida Rocca et al. ${ }^{10}$ who used the SSI to compare euthymic patients with bipolar disorders with normal controls using the SSI also found no differences between groups on the domains one, two and five. It is important to emphasize that use of medication may explain these findings, particularly on domain five (self-control of aggressiveness), since bipolar patients were receiving lithium in monotherapy or in combination with antipsychotics or anticonvulsants, which are drugs with proven anti-aggression and impulse control proprieties ${ }^{17}$.

The present study showed that the SSI may represent a useful tool for evaluation of social skills in schizophrenia and the lack of differences between groups may be explained by the use of antipsychotics, which may exert a protective effect on social skills. Future studies are warranted to validate the SSI - Del-Prette for the evaluation of social skills in patients with schizophrenia.

\section{Source of funding}

The study was funded by the São Paulo Research Foundation (Fapesp - grant number 2009/13934-6). 


\section{Conflict of interests}

Hélio Elkis MD $\mathrm{PhD}$ has received research grants from Fapesp, Roche and Janssen and received honoraria as speaker, travel support or board participation from Ache, Roche, Janssen, Cristalia and Daiichy-Sankyo. Other participants have no conflicts of interests to disclose.

\section{Acknowledgements}

Luciana Monteiro, Vanessa Cunha e Ellen Aversari for the application of the SSI - Del-Prette.

\section{References}

1. Haro JM, Altamura C, Corral R, Elkis H, Evans J, Malla A, et al. Understanding the impact of persistent symptoms in schizophrenia: Cross-sectional findings from the Pattern study. Schizophr Res. 2015;169(1-3):234-40.

2. American Psychiatric Association. Diagnostic and Statistical Manual of Mental Disorders - DSM-5. 5th ed. Washington DC: American Psychiatric Press; 2013.

3. Elkis H, Buckley PF. Treatment-Resistant Schizophrenia. Psychiatr Clin North Am. 2016;39(2):239-65.

4. Mueser K, Glyn S, McGurk S. Social and Vocational Impairments. Textbook of Schizophrenia. Washington DC: American Psychiatric Publishing Inc.; 2006.

5. Liberman RP. Assessment of social skills. Schizophr Bull. 1982;8(1):62-83.

6. Pfammatter M, Junghan UM, Brenner HD. Efficacy of psychological therapy in schizophrenia: conclusions from meta-analyses. Schizophr Bull. 2006;32 Suppl 1:S64-80.

7. Kurtz MM, Mueser KT. A meta-analysis of controlled research on social skills training for schizophrenia. J Consult Clin Psychol. 2008;76(3):491-504.

8. Del Prette ZAP, Del Prette A. Inventário de Habilidades Sociais (IHSDel-Prette). Manual de aplicação, apuração e interpretação. São Paulo: Casa do Psicólogo; 2001.

9. Del Prette ZAP, Del Prette A. Social Skills Inventory: Characteristics and Studies in Brazil. In: Osorio FL, editor. Social Anxiety Disorder: From Research to Practice. Psychology Research Progress. Ribeirão Preto, São Paulo, Brazil: Nova Science Publishers, Inc.; 2013. p. 47-60.

10. de Almeida Rocca CC, de Macedo-Soares MB, Gorenstein C, Tamada RS, Issler CK, Dias RS, et al. Social dysfunction in bipolar disorder: pilot study. Aust N Z J Psychiatry. 2008;42(8):686-92.
11. Kay SR, Fiszbein A, Opler LA. The positive and negative syndrome scale (PANSS) for schizophrenia. Schizophr Bull. 1987;13(2):261-76.

12. Association AP. Diagnostic and Statistical Manual of Mental Disorders. 4th ed. Text Revised. Washington DC: American Psychiatric Press; 2000.

13. IPAP. Schizophrenia Algorithm. Available at: <http://www.ipap.org/ algorithms.php>.

14. Elkis H. Refractory schizophrenia. Rev Bras Psiquiatr. 2007;29 (suppl. 2):S41-7.

15. Woods SW. Chlorpromazine equivalent doses for the newer atypical antipsychotics. J Clin Psychiatry. 2003;64(6):663-7.

16. Woods SW. Calculation of CPZ Equivalents. Available at: www. scottwilliamwoods.com/files/Equivtext.doc. 2005.

17. Citrome L, Volavka J. The psychopharmacology of violence: making sensible decisions. CNS Spectr. 2014;19(5):411-8.

18. Hersen M, Turner SM, Edelstein BA, Pinkston SG. Effects of phenothiazines and social skills training in a withdrawn schizophrenic. J Clin Psychol. 1975;31(4):588-94.

19. Marder SR, Wirshing WC, Mintz J, McKenzie J, Johnston K, Eckman TA, et al. Two-year outcome of social skills training and group psychotherapy for outpatients with schizophrenia. Am J Psychiatry. 1996;153(12):1585-92.

20. Buchanan RW. Persistent negative symptoms in schizophrenia: an overview. Schizophr Bull. 2007;33(4):1013-22.

21. Kelley ME, van Kammen DP, Allen DN. Empirical validation of primary negative symptoms: independence from effects of medication and psychosis. Am J Psychiatry. 1999;156(3):406-11.

22. Murphy BP, Chung YC, Park TW, McGorry PD. Pharmacological treatment of primary negative symptoms in schizophrenia: a systematic review. Schizophr Res. 2006;88(1-3):5-25.

23. Matousek N, Edwards J, Jackson HJ, Rudd RP, McMurray NE. Social skills training and negative symptoms. Behav Modif. 1992;16(1):39-63.

24. Kopelowicz A, Liberman RP, Mintz J, Zarate R. Comparison of efficacy of social skills training for deficit and nondeficit negative symptoms in schizophrenia. Am J Psychiatry. 1997;154(3):424-5.

25. Grimes D, Schultz K. An overview of clinical research: the lay in the land. Lancet. 2002;359:57-61.

26. Leucht S, Kane JM, Kissling W, Hamann J, Etschel E, Engel RR. What does the PANSS mean? Schizophr Res. 2005;79(2-3):231-8.

27. Saykin AJ, Shtasel DL, Gur RE, Kester DB, Mozley LH, Stafiniak P, et al. Neuropsychological deficits in neuroleptic naive patients with firstepisode schizophrenia. Arch Gen Psychiatry. 1994;51(2):124-31.

\section{Errata}

\section{Social dysfunction and skills in schizophrenia: relationship with treatment response and severity of psychopathology}

Scemes S et al. / Arch Clin Psychiatry. 2016;43(5):107-11

DOl: 10.1590/0101-60830000000111

Where you read:

Hélio Elkis ${ }^{1}$, Silvia Scemes ${ }^{1}$, Mariangela Gentil Savoia ${ }^{1}$, Zilda Del Prette² ${ }^{2}$ Paulo Mestriner ${ }^{1}$, Aline Roberta da Silva ${ }^{1}$

Should read:

Silvia Scemes ${ }^{1}$, Mariangela Gentil Savoia ${ }^{1}$, Zilda Del Prette², Paulo Mestriner ${ }^{1}$, Aline Roberta da Silva ${ }^{1}$, Hélio Elkis ${ }^{1}$ 